\title{
First Record of the Grenadier Coelorinchus sheni (Actinopterygii: Gadiformes: Macrouridae) from Japan
}

\author{
Naohide Nakayama ${ }^{1,2,5}$, Hiroko Takaoka ${ }^{3}$, and Kei Miyamoto ${ }^{4}$ \\ ${ }^{1}$ The Kyoto University Museum, Kyoto University, Yoshida, Sakyo, Kyoto 606-8501, Japan \\ E-mail: gadiformes@gmail.com \\ ${ }^{2}$ Present address: Department of Marine Biology, School of Marine Science and Technology, Tokai University, \\ 3-20-1 Orido, Shimizu, Shizuoka 424-8610, Japan \\ ${ }^{3}$ Okinawa Churaumi Aquarium, 424 Ishikawa, Motobu, Kunigami, Okinawa 905-0206, Japan \\ ${ }^{4}$ Okinawa Churashima Research Center, 888 Ishikawa, Motobu, Kunigami, Okinawa 905-0206, Japan \\ ${ }^{5}$ Corresponding author
}

(Received 21 September 2017; Accepted 24 November 2017)

\begin{abstract}
The rarely caught grenadier, Coelorinchus sheni Chiou, Shao and Iwamoto, 2004, is newly recorded from Japanese waters, based on a single specimen (196 mm in head length, $692+\mathrm{mm}$ in total length) collected from the East China Sea off the north-west coast of Ie-jima island, Okinawa, at a depth of $650 \mathrm{~m}$. It belongs to the C. tokiensis group, and readily differs from other Japanese congeners in having a series of dark saddles on the body, a fully-scaled underside of the head, and a short light organ anterior to the anus (its anterior tip falling far short of a line connecting the inner pelvic-fin bases), and in lacking a complete bony support of the lateral nasal ridge. The morphology of the Japanese specimen is fully described, with the first report of the species' fresh coloration. Localities of type specimens of C. sheni are also emended. Coelorinchus sheni was previously known only from Taiwan; thus the Japanese specimen represents the first record of the species from outside Taiwanese waters and the northernmost record of the species.
\end{abstract}

Key Words: Deep-sea fish, range extension, distribution, Okinawa, East China Sea.

\section{Introduction}

The grenadier genus Coelorinchus Giorna, 1809 is by far the largest group of the gadiform family Macrouridae, comprising about 120 valid species (Iwamoto et al. 2015; Nakayama and Endo 2017), 24 of which are known from Japanese waters (Nakabo and Kai 2013; Nakayama et al. 2015). The genus is distinguished from other grenadier genera by having the following combination of features: snout prominent, tipped with a modified scute; infraorbital and preopercular ridges tightly connected, forming a stout, continuous, bony ridge; second spinous ray of first dorsal fin smooth along its leading edge (rudimentary denticles occasionally found distally); no rakers on outer side of first gill arch (a few rakers rarely found in large individuals); anus immediately anterior to, or slightly removed from, anal-fin origin (in most species); pelvic-fin rays almost always seven, rarely six; branchiostegal rays six (Iwamoto 1990; Iwamoto and Merrett 1997; Iwamoto and Williams 1999; Nakayama and Endo 2017; this study).

Coelorinchus sheni was originally described by Chiou et al. (2004) based on three specimens collected from Taiwan. Subsequently, Iwamoto et al. (2015) reported 10 additional specimens of the species from the type locality. Interestingly, no specimens of this species were recorded from the vicinity of Okinawa, Japan, despite its close geographical proximity to Taiwan and intensive collecting efforts in deep-waters in the East China Sea by previous Japanese re- searchers (e.g., Okamura and Kitajima 1984; Okamura 1985; Yamada et al. 1986, 2007; Shinohara et al. 2005; Furuhashi et al. 2010).

On 15 September 2016, a large specimen of Coelorinchus was collected by long-line fishing in the East China Sea off the northwestern coast of Ie-jima island, Okinawa, southern Japan. The fish was subsequently donated to the Okinawa Churashima Foundation, and further examination revealed that it represents the first record of $C$. sheni from outside Taiwanese waters. Here we provide a full description of the Japanese specimen, and propose a new standard Japanese name for the species.

\section{Materials and Methods}

Methods for taking counts and making measurements follow Iwamoto (1970), Iwamoto and Sazonov (1988), and Nakayama et al. (2015). The terminology of head ridges is that redefined by Nakayama et al. (2015). The head, postrostral, and total lengths are expressed as HL, PRL, and TL, respectively. The Japanese specimen is deposited in the fish collection of the Okinawa Churashima Research Center, Okinawa Churashima Foundation, Okinawa (OCF-P). Comparative specimens examined are in the Academia Sinica, Taipei (ASIZP), the Laboratory of Marine Biology, Faculty of Science, Kochi University, Kochi (BSKU), and the California Academy of Sciences, San Francisco (CAS). Other institutional abbreviations follow Fricke and Esch- 


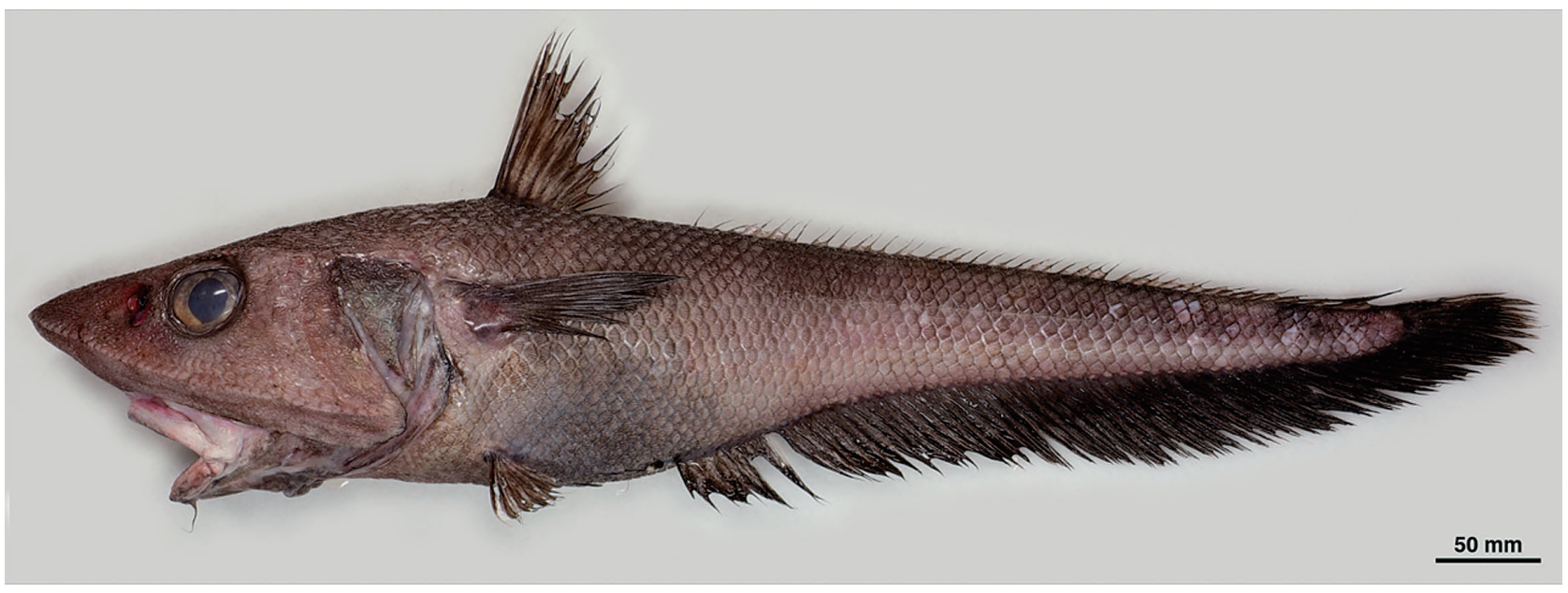

Fig. 1. Fresh specimen of Coelorinchus sheni in lateral view. OCF-P03492, $196 \mathrm{~mm}$ HL, 692+ mm TL, East China Sea, north-west of Iejima island, Okinawa, Japan, $650 \mathrm{~m}$ depth.

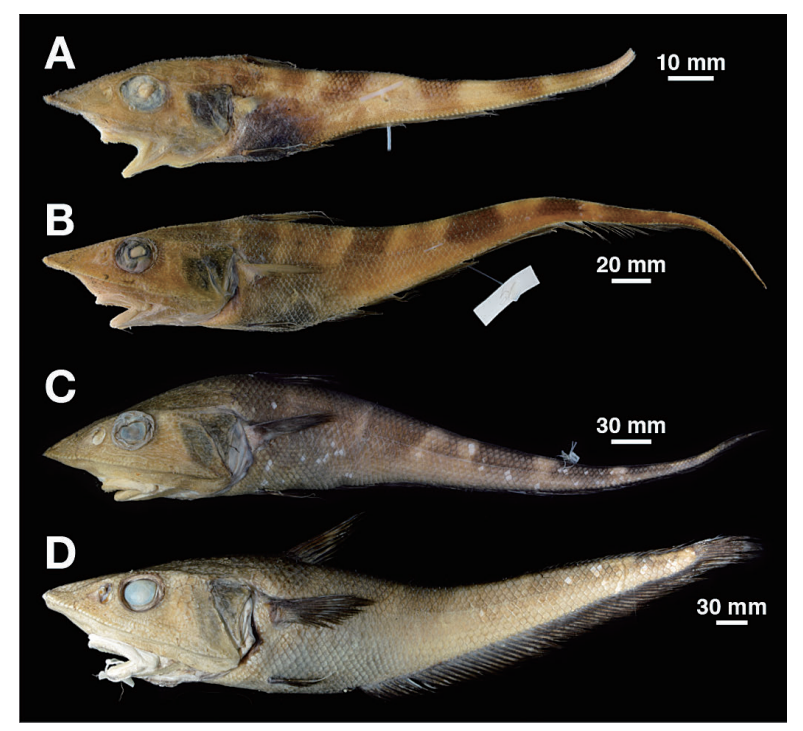

Fig. 2. Preserved specimens of Coelorinchus sheni in lateral view. (A-C) Da-xi fish market, northeastern Taiwan, and (D) north-west of Ie-jima island, Okinawa, Japan. (A) ASIZP 70210, $41.3 \mathrm{~mm}$ HL, $86+\mathrm{mm}$ TL, (B) ASIZP 70210, $98.8 \mathrm{~mm} \mathrm{HL}, 380+\mathrm{mm} \mathrm{TL},(\mathrm{C})$ BSKU 116471, $154 \mathrm{~mm}$ HL, 558+ mm TL, and (D) OCF-P03492, $196 \mathrm{~mm} \mathrm{HL}, 692+\mathrm{mm}$ TL.

meyer (2017). Species scientific names were checked using Eschmeyer et al. (2017).

Coelorinchus sheni Chiou, Shao and Iwamoto, 2004 [New standard Japanese name: Tora-hige] (Figs 1, 2; Table 1)

Caelorinchus sheni Chiou, Shao and Iwamoto, 2004: 37, figs 1-4 [original description; holotype: ASIZP 61348, from off "Tashi" (=Da-xi), northeastern Taiwan, $24.91^{\circ} \mathrm{N}$, $122.06^{\circ} \mathrm{E}, 400-600 \mathrm{~m}$ (not “ $24^{\circ} 54^{\prime} 63^{\prime \prime} \mathrm{N}, 120^{\circ} 03^{\prime} 49^{\prime \prime} \mathrm{E}$, 400-650 m; see Remarks); 2 paratypes from northeastern and southeastern Taiwan].

Coelorinchus sheni: Shao et al. 2008: table 2 (3 spec. listed from northeastern and "southwestern" Taiwan, 100$650 \mathrm{~m}$ ); Ho and Shao 2011: 36 (type catalog); Iwamoto et al. 2015 (13 spec.; brief description; northeastern and southeastern Taiwan, $c a .100-650 \mathrm{~m}$ ).

Specimen examined. OCF-P03492 (1 specimen, female, $196 \mathrm{~mm}$ HL, 692+ mm TL), Izena Bank, north-west of Ie-jima island, Okinawa, Nansei Islands, East China Sea, $27^{\circ} 08.055^{\prime} \mathrm{N}, 127^{\circ} 14.420^{\prime} \mathrm{E}, 650 \mathrm{~m}$ depth, coll. T. Arakaki, 15 September 2016.

Diagnosis. Light organ represented by short black streak in front of anus (difficult to distinguish in some specimens), its anterior tip falling far short of pelvic-fin bases. Underside of head completely and uniformly covered with scales, except for anterior portions of mandibular rami. Snout long, length 40-43\% HL (66-73\% PRL), dorsal profile straight or slightly convex in lateral view. Snout acutely pointed distally, terminating with conical scute. Lateral nasal ridge incompletely supported by nasal bone. Dorsal surface of snout fully scaled. Anus immediately anterior to anal-fin origin, but slightly separated by a few scale rows. Premaxillary teeth in long tapered band, outer series prominently enlarged; posterior end of tooth band reaching near lateral corner of mouth. Body scales covered with short, reclined, blade-like spinules in widely divergent, saw-toothed ridges; spinules in each row overlapping but free at tips, gradually increasing in height posteriorly; buttresses of spinules poorly developed. Scales atop head between parietal ridges covered with 2-4 divergent rows of spinules. About six dark saddles on trunk and tail; lips paler; oral cavity blackish; gular and branchiostegal membranes dusky.

Description of Japanese specimen. General features shown in Figs 1 and 2D. Counts and measurements given in Table 1.

Body deepest below first dorsal-fin origin, gradually tapering to long tail. Trunk moderately compressed, width over pectoral-fin bases 1.4 in depth below first dorsal-fin origin. Head large, HL less than 3.5 in TL (large pseudocau- 
Table 1. Measurements and counts for Coelorinchus sheni*.

\begin{tabular}{|c|c|c|c|c|}
\hline \multirow{3}{*}{$\begin{array}{c}\text { Locality } \\
\text { Type status } \\
\text { Number of specimens }\end{array}$} & Japan & \multicolumn{3}{|c|}{ Taiwan } \\
\hline & Non-type & Holotype & Paratype & Non-types \\
\hline & $n=1$ & $n=1$ & $n=1$ & $n=7$ \\
\hline \multicolumn{5}{|l|}{ Measurements (mm) } \\
\hline Total length (TL) & $692+$ & $412+$ & $424+$ & $86+-558+$ \\
\hline Head length (HL) & 196 & 115 & 112 & $41.3-154$ \\
\hline \multicolumn{5}{|l|}{$\%$ of HL (\% of PRL) } \\
\hline Snout length & $40(66)$ & $41(69)$ & $41(68)$ & $41-43(67-73)$ \\
\hline Orbit diameter & $21(35)$ & $22(37)$ & $22(37)$ & $21-27(35-44)$ \\
\hline Postorbital length & $39(65)$ & $38(64)$ & $39(64)$ & $35-40(58-65)$ \\
\hline Postrostral length (PRL) & $61(-)$ & $59(-)$ & $60(-)$ & $58-61(-)$ \\
\hline Orbit-preopercle distance & $46(76)$ & $39(66)$ & $42(69)$ & $36-42(59-70)$ \\
\hline Suborbital width & $15(25)$ & $14(24)$ & $14(23)$ & $12-14(21-23)$ \\
\hline Upper-jaw length & $36(59)$ & $30(51)$ & $27(45)$ & $27-32(45-52)$ \\
\hline Preoral length & $29(48)$ & $30(51)$ & $30(49)$ & $29-35(47-59)$ \\
\hline Internasal width & $17(28)$ & $18(30)$ & $19(32)$ & $17-21(28-34)$ \\
\hline Interorbital width & $25(41)$ & $25(43)$ & $26(43)$ & $24-26(39-43)$ \\
\hline Occipital width & $9(14)$ & $10(16)$ & $9(15)$ & $9-11(15-18)$ \\
\hline Body width over P. bases & $47(77)$ & $40(67)$ & $41(69)$ & $36-45(59-73)$ \\
\hline Body depth at 1D. origin & $65(107)$ & $58(97)$ & - & $54-58(90-97)$ \\
\hline Body depth at A. origin & $54(89)$ & $47(79)$ & - & $43-50(71-83)$ \\
\hline Pre-V. length & $114(187)$ & $102(171)$ & $109(180)$ & $103-113(173-192)$ \\
\hline Pre-anus length & $148(244)$ & - & - & $129-138(214-234)$ \\
\hline Pre-A. length & $154(252)$ & $137(230)$ & $141(233)$ & $133-143(222-243)$ \\
\hline Isthmus-V. distance & $39(64)$ & $33(55)$ & $33(55)$ & $28-31(46-53)$ \\
\hline Isthmus-anus distance & $74(122)$ & - & - & $52-59(86-98)$ \\
\hline Isthmus-A. distance & $80(131)$ & $68(114)$ & $63(105)$ & $58-65(96-108)$ \\
\hline V.-A. distance & $46(75)$ & $39(65)$ & $33(54)$ & $32-37(52-62)$ \\
\hline Anus-A. distance & $6(10)$ & - & - & $5-7(7-12)$ \\
\hline V. length & $42(69)$ & $39(66)$ & $33(54)$ & $35-56(57-93)$ \\
\hline P. length & $52(86)$ & $48(80)$ & $48(80)$ & $45-49(77-83)$ \\
\hline Pre-1D. length & $112(183)$ & $107(180)$ & $107(178)$ & $105-107(173-182)$ \\
\hline Height of 1D. & $50(82)$ & - & - & $42-50(69-82)$ \\
\hline Length of $1 \mathrm{D}$. base & $21(34)$ & $19(33)$ & $18(30)$ & $17-20(29-33)$ \\
\hline Interdorsal length & $28(46)$ & $22(38)$ & $16(27)$ & $12-23(20-37)$ \\
\hline Length of gill slit & $19(32)$ & $16(27)$ & $16(26)$ & $13-17(22-29)$ \\
\hline Length of posterior nostril & $9(15)$ & $7(12)$ & $9(15)$ & $8-9(14-15)$ \\
\hline Barbel length & $13(21)$ & $10(17)$ & $8(13)$ & $8-10(13-16)$ \\
\hline \multicolumn{5}{|l|}{ Counts } \\
\hline 1D. rays & II, 8 & II, 8 & II, 8 & II, 8-9 \\
\hline P. rays & i17 & i17-i19 & i18-i19 & $\mathrm{i} 18-\mathrm{i} 20$ \\
\hline V. rays & 7 & 7 & 7 & 7 \\
\hline Outer GR on first arch & 1 & 1 & 1 & $0-3$ \\
\hline Inner GR on first arch & 9 & 8 & 9 & $8-9$ \\
\hline Outer GR on second arch & 6 & 6 & 8 & $6-7$ \\
\hline Inner GR on second arch & 10 & 9 & 9 & 9 \\
\hline Lateral-line scales & 33 & 38 & 36 & $34-43$ \\
\hline Scales below 1D. origin & 5.5 & 6.5 & 6.5 & $5.5-6.5$ \\
\hline Scales below 1D. midbase & 5.5 & 4.5 & 4.5 & $4-5.5$ \\
\hline Scales below 2D. origin & 5.5 & 6 & 5.5 & $5-6$ \\
\hline Pyloric caeca & ca. 58 & - & - & ca. $46^{* *}$ \\
\hline
\end{tabular}

* 1D., first dorsal fin; 2D., second dorsal fin; P., pectoral fin; V., pelvic fin; A., anal fin; GR, gill rakers.

**B Based on 1 specimen (BSKU 116417).

dal developed). Snout long, protruding well beyond upper jaw, length 1.9 times orbit diameter; dorsal profile gently convex in lateral view; snout bluntly pointed in lateral view, tipped with acute scute; lateral nasal ridge incompletely sup- ported by nasal bone; anterolateral margins slightly convex when viewed dorsally. Orbit large, almost circular, greatest diameter 1.9 in postorbital length. Interorbital space broad, slightly concave, width 0.8 in orbit diameter. Mouth large, 
inferior, protrusible; upper-jaw length 0.6 in orbit diameter; posterior end of maxilla slightly anterior to vertical through hind rim orbit; lateral corner of mouth slightly restricted by lip folds; lips thick, papillose near teeth. Suborbital region divided into dorsal and ventral parts by longitudinal ridge passing from tip of snout to posterior angle of preopercle; dorsal part flat, almost vertical; ventral part concave, moderately inclined mesially. Preopercle large, posterior margin inclined, forming broad angular lobe at posteroventral corner. Interopercle completely covered by preopercle. Subopercle bluntly angulated posteroventrally; posterior margin concave. Gill membranes thick, narrowly connected across isthmus, with slight posterior free fold. Branchiostegal rays six. Gill opening wide, extending forward to below posterior end of lower jaw. Outer gill slit moderately restricted by folds of skin, length 1.1 in orbit diameter. Gill rakers ridgelike, armed with short, fine spines; one rudimentary raker on outer side of first gill arch (immediately below corner); no rakers on inner side of fourth arch; gill filaments well-developed and long. Chin barbel slender, hairlike at tip, length 1.7 in orbit diameter.

Anus slightly separated from anal fin origin. Light organ short, its anterior tip falling well short of midpoint between anus and inner pelvic-fin base, not reaching posterior $1 / 3$ of pelvic-anus distance.

Teeth small, conical, slender, slightly incurved, in long tapering bands in both jaws. Premaxillary band with about 4-5 tooth rows anteriorly, outer series distinctly enlarged; other teeth becoming progressively smaller inwardly; posterior end of tooth band reaching near lateral corner of mouth (tooth band occupying about 3/4 of rictus length). Mandibular teeth uniformly small, arranged in about five rows across widest point of symphysis; posterior end of tooth band extending to lateral corner of mouth. All teeth deeply embedded in thick layer of gum papillae.

Body scales large, adherent, covered with short, reclined, blade-like spinules in widely divergent, saw-toothed rows; those on dorsum below interdorsal space with 7-8 rows of spinules; middle row usually longest, with about 6-8 spinules, but not especially high or enlarged compared with adjacent rows; spinule rows complete throughout; spinules greatly overlapping, closely adjoining one another, but distal tips usually free, forming saw-toothed ridges; spinules forming an angle of about $40^{\circ}$ to scale surface, increasing in height posteriorly, with last in each row extending slightly beyond posterior scale margin; buttresses of spinules poorly developed; no reticulate structures on unexposed potion. Body fully scaled except for fins and ventral light organ.

Scales on head ridges thickened, moderately spinulated; those on median nasal ridges covered with divergent rows of spinules. Terminal snout scute short, arrowhead-shaped, dorsoventrally depressed, a pair of adjacent scales also modified, much smaller than terminal scute and distinctly larger than those posterior. No prominent, tubercular scales on supraoccipital region; posttemporal scutes small, elongate, armed with single row of spinules. Snout completely scaled dorsally (naked clefts along each side of median ros- tral ridge absent). Scales on dorsal surfaces of head (including space between parietal ridges) covered with short, erect, blade-like spinules in 2-4 divergent rows; spinules adjoined basally to one another, forming saw-toothed ridges that increase in height posteriorly. Underside of head completely and uniformly scaled, except for anterior 1/4 of mandibular rami; scales armed with short, erect, blade-like spinules in uniserial row (occasionally 2-3 rows); spinules broadly adjoining one another, forming crest-like ridge. Nasal fossa heavily scaled ventrally and anterodorsally. Other scales on dorsal and lateral surfaces of head variable in size, generally similar to those on body, but spinules more erect; those on opercle, preopercle, and postorbital and temporal canals largest.

Cephalic sensory pores absent. Free neuromasts small but conspicuous, serially arranged along head ridges (except on underside of head) and mandibular rami. Anterior nostril small, circular, directed anterolaterally; posterior nostril large, crescent-shaped; septum between nostrils forming anteriorly opened hood. Lateral line complete, extending from upper margin of opercle to end of tail.

First dorsal-fin origin slightly posterior to upper pelvicfin base; fin moderately high, height 2.4 times base length; second spinous ray not prolonged, extending posteriorly to about second dorsal-fin origin when laid back; leading edge of second spinous ray entirely smooth, except for small, rudimentary denticles near distal tip. Interdorsal space 1.4 times first dorsal-fin base length. Second dorsal fin poorly developed throughout, origin above base of second anal-fin ray. Pectoral fin inserted slightly anterior to pelvic-fin base; tip of pectoral fin extending posteriorly to vertical through second dorsal-fin origin. Outer pelvic-fin ray moderately prolonged with fine distal tip, extending posteriorly to about anal-fin origin when laid back.

Color when fresh. Based on Fig. 1. Head and body dark brownish overall, much darker dorsally; abdomen dark, with slightly bluish tinge, but chest and shoulder girdle paler; about six faint, broad, dark saddles dorsally on body; first narrow, situated below first dorsal-fin origin; second broad, covering most of interdorsal space and anterior few rays of second dorsal fin; remaining bands on tail, with their lower margins reaching or extending slightly beyond midlateral axis of body; opercle much darker than surrounding areas; orbit faintly outlined by dark brown; jaws mostly pale, but lips dark along mouth opening; chin barbel dark; gular and branchiostegal membranes dusky. Fins uniformly dark brown, but anal fin much darker than others, and first dorsal and pelvic fin tipped with white.

Color in $\mathbf{7 0} \%$ ethanol after $\mathbf{1 0} \%$ formalin fixation. See also Fig. 2D. Similar to fresh condition, but generally much paler, with ground color of head and body tawny; oral cavity blackish, gill cavity dull black; gill rakers pale, filaments and arches dusky.

Distribution. Known from Taiwan (Chiou et al. 2004; Iwamoto et al. 2015) and Japan (this study) at depths of about 400-650 m: off Da-xi (type locality) in Yilan, northeastern Taiwan; the east of Lauto in Taitung, southeastern Taiwan; and off Ie-jima island in Okinawa, Nansei Islands, 


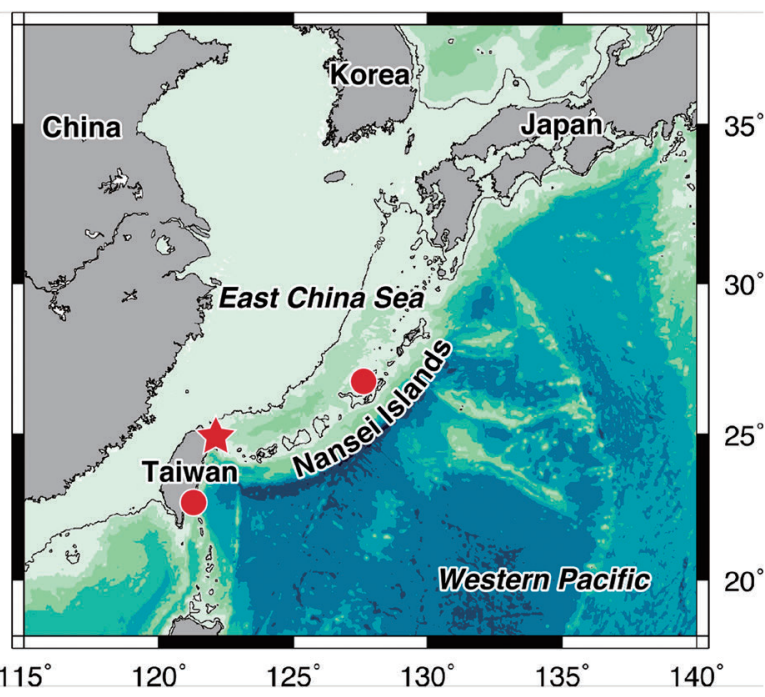

Fig. 3. Distribution of Coelorinchus sheni. Star indicates type locality.

southern Japan (Fig. 3; see also Remarks).

Remarks. Coelorinchus sheni was originally described by Chiou et al. (2004) based on three specimens collected from Taiwan. Nine Taiwanese specimens of $C$. sheni, including the holotype and one paratype, were examined here to confirm the identification of the Japanese specimen. The Japanese specimen possesses the species' diagnostic features (see Diagnosis), and agrees well with the Taiwanese specimens examined as well as previous descriptions of C. sheni given by Chiou et al. (2004) and Iwamoto et al. (2015). Although the presence of prominent saddles on the body was regarded as one of the diagnostic features of C. sheni (e.g., Chiou et al. 2004; Iwamoto et al. 2015), those of the Japanese specimen are less pronounced than the Taiwanese specimens examined (Figs 1 and 2D vs. Figs 2A-C). However, the Japanese specimen is distinctly larger than the Taiwanese specimens (196 mm HL, 692+ mm TL vs. 41.3$154 \mathrm{~mm} \mathrm{HL}, 86+-558+\mathrm{TL})$, and the difference appears to reflect size-related variation. Nakayama et al. (2015) reported similar variation in C. tokiensis (Steindachner and Döderlein, 1887), a closely related congener (see below), which further supports this conclusion. Iwamoto et al. (2015) noted the number of pyloric caeca of C. sheni as about 27, whereas the Japanese specimen has about 58. A $154 \mathrm{~mm}$ HL Taiwanese specimen examined (BSKU 116417) also had a higher count of pyloric caeca (ca. 46). However, the discrepancy between Iwamoto et al. (2015) and this study is too obvious to neglect, and requires later verification. Meristic and morphometric data of the Japanese specimen generally lie within or slightly outside the rage of variation of the Taiwanese specimens examined, except for the following characters: orbit-preopercle distance (76\% PRL in Japanese specimen vs. 59-70\% PRL in Taiwanese specimens), upper-jaw length ( $59 \%$ vs. 45-52\%), body width over pectoral-fin bases $(77 \%$ vs. $59-73 \%)$, body depths at first dorsal- (107\% vs. $90-97 \%)$, and anal-fin origins (89\% vs. 71-83\%), preanus length (244\% vs. 214-234\%), preanal-fin length (252\% vs. $222-243 \%)$, distances from isthmus to pel- vic-fin origin (64\% vs. $46-53 \%)$, to anus (122\% vs. 86-98\%), and to anal-fin origin (131\% vs. $96-108 \%)$, distance from pelvic-fin base to anal-fin origin ( $75 \%$ vs. $52-62 \%)$, interdorsal length ( $46 \%$ vs. $20-37 \%)$, and barbel length (21\% vs. 13-16\%). These differences appear distinctive, but considering the large size of the Japanese specimen and the limited number of available materials, they are most likely attributable to size-related variation.

In Japanese waters, C. sheni is most similar to C. hexafasciatus Okamura, 1982 and C. tokiensis [a senior synonym of C. longicephalus Okamura 1982; see Nakayama et al. (2015)]. They all belong to the C. tokiensis group as redefined by Nakayama et al. (2015) in sharing the following combination of features: light organ short, length less than half orbit diameter, its anterior tip falling well short of pelvic-fin bases (external sign of light organ difficult to distinguish in some specimens); dorsal profile of snout almost straight in lateral view; lateral nasal ridge incompletely supported by nasal bone; premaxillary teeth in long tapering band, with outer series enlarged; posterior end of premaxillary tooth band extending near lateral corner of mouth; body scales covered with blade-like spinules in widely divergent, saw-toothed rows; a series of dark saddles on body; oral cavity blackish. However, C. sheni is unlikely to be confused with these two species in that the underside of the head is completely and uniformly covered with scales, except for anterior portions of the mandibular rami (vs. broadly naked and scaly areas confined to the ventral surfaces of the preopercles) (Nakayama et al. 2015). Coelorinchus smithi Gilbert and Hubbs, 1920 is another Japanese species superficially similar to C. sheni, but it belongs to the C. japonicus group as redefined by Nakayama and Endo (2017). As noted above, the dark saddles of $C$. sheni become fainter with growth, and except for the difference in the color pattern, C. sheni is generally similar to C. smithi in overall appearance, head squamation, morphology of the body scales, and development of the light organ. Although these similarities might lead to misidentifications of the two species, C. sheni differs most notably from C. smithi in lacking a complete bony support for the lateral nasal ridge $[v s$. lateral nasal ridge completely supported by nasal bone; see Okamura (1970): fig. 32C'].

The type locality of C. sheni given by Chiou et al. (2004) and Ho and Shao (2011) is problematic. In the original description of the species, Chiou et al. (2004: 37) noted that the holotype (ASIZP 61348) was collected from off Tashi (=Da-xi, northeastern Taiwan), “24 $54^{\circ} 63^{\prime \prime} \mathrm{N}, 120^{\circ} 03^{\prime} 49^{\prime \prime} \mathrm{E}$ ” (probably $24^{\circ} 54.63^{\prime} \mathrm{N}, 120^{\circ} 03.49^{\prime} \mathrm{E}$ ), at a depth of $400-$ $650 \mathrm{~m}$. In their type catalog of Taiwanese fishes, Ho and Shao (2011) also referred to the same data for this specimen. However, the above coordinates refer to a position in the Taiwan Strait (western Taiwan), where the bottom depth is less than $100 \mathrm{~m}$. Conversely, according to the Fish Database of Taiwan (Shao 2017), the coordinates and bottom depth of the type locality are given as $24.91^{\circ} \mathrm{N}, 122.06^{\circ} \mathrm{E}$ (east of Daxi) and 400-600 m, respectively. Hsuang-Ching Ho (pers. comm., 30 May 2017) of the National Museum of Marine Biology and Aquarium, who worked at ASIZP when the 
type specimens of $C$. sheni were collected, informed us that the holotype was apparently from off Da-xi. Based on this information, we follow the data given by Shao (2017) for the type locality of this species. Similarly, Chiou et al. (2004: 39 ) and Iwamoto et al. (2015: 67) noted C. sheni to be distributed in northeastern and southeastern Taiwan, but the occurrence in the latter area requires confirmation. The record from southeastern Taiwan is based only on a paratype (ASIZP 61232; not examined in this study) collected from Lauto [=Lyu-dao (commonly known as Green Island)] at “22 $20^{\prime} 05^{\prime \prime} \mathrm{N}, 120^{\circ} 12^{\prime} 12^{\prime \prime} \mathrm{E} "$ (Chiou et al. 2004: 37; Iwamoto et al. 2015: 67) in Taitung. However, these coordinates indicate a position in the northern part of the South China Sea, west of Hsiao-liu-chiu (=Xiaoliuqiu) in Pingtung, southwestern Taiwan. Shao et al. (2008: table 2) emended the record, stating that $C$. sheni is distributed in southwestern instead of southeastern Taiwan, but according to H.-C. Ho (pers. comm., 6 June 2017), the specimen was definitely collected from east of Lauto $\left(c a .22^{\circ} 40^{\prime} \mathrm{N}, 121^{\circ} 40^{\prime} \mathrm{E}\right)$ while recreational fishing with a rod and reel.

The bathymetric distribution of $C$. sheni is also open to discussion, although Shao et al. (2008) and Iwamoto et al. (2015) indicated it as $100-650 \mathrm{~m}$. The upper end of this range comes from records of specimens obtained at the Da-xi fish market, of which fishers operate their bottom trawls at depths of about 100-650 m (Shao et al. 2008: table 1). Obviously, Shao et al.'s (2008) and Iwamoto et al.'s (2015) statements were not erroneous, but the depth range of the fishery does not necessarily represent the bathymetric distribution of C. sheni. Based only on specimens associated with reliable depth records, viz. the holotype (400-600 m) (Shao 2017) and the Japanese specimen (650 m) (this study), we can say only that the species is vertically distributed in $400-650 \mathrm{~m}$.

The specimen herein reported from off Ie-jima island, Okinawa, represents the first record of C. sheni from Japanese waters and the northernmost record of the species. It extends the known range of $C$. sheni approximately $600 \mathrm{~km}$ northeastward from Taiwan (Fig. 3). The occurrence of C. sheni in Japanese waters seems to be incidental, but the southern slope of the Okinawa Trough has not been thoroughly investigated [see Okamura and Kitajima (1984): figs 1, 2; Shinohara et al. (2005): fig. 1]. Therefore, further collecting efforts in such a poorly explored area of the East China Sea may result in additional specimens of C. sheni. A new standard Japanese name, "Tora-hige", is proposed here for C. sheni based on the specimen OCF-P03492. This name is derived from Japanese common names for tigers (=tora) and grenadiers (=hige), in reference to the species' saddle markings.

Comparative specimens examined. Coelorinchus sheni (9 specimens, 41.3-154 mm HL, $86+-558+$ mm TL): ASIZP 61348 (holotype, $115 \mathrm{~mm} \mathrm{HL}, 412+\mathrm{mm} \mathrm{TL}$ ), off Da-xi, Yilan, East China Sea, $24.91^{\circ} \mathrm{N}, 122.06^{\circ} \mathrm{E}, 400-600 \mathrm{~m}$ depth, F/V Gin Ton Long, bottom trawl, coll. by M.-L. Qiu, 30 May 2001 [data from Shao (2017)]; CAS 215541 (paratype, $112 \mathrm{~mm} \mathrm{HL}, 424+\mathrm{mm} \mathrm{TL}$ ), Da-xi fish market, Yilan, northern Taiwan, coll. M.-L. Chiou and H.-C. Ho, date unknown [data from CAS (2017)]; ASIZP 70210 (6, 41.3$98.8 \mathrm{~mm} \mathrm{HL}, 86+-380+\mathrm{mm}$ TL), Da-xi fish market, Yilan, northwestern Taiwan, coll. by M.-L. Qiu, 25 June 2005; BSKU 116417 (1, $154 \mathrm{~mm}$ HL, 558+ mm TL), Da-xi fish market, Yilan, northwestern Taiwan, coll. by H.-C. Ho, 18 June 2014.

\section{Acknowledgments}

We are grateful to T. Arakaki (Itoman) for his help in collecting the Japanese specimen. We also thank S.-P. Huang and P.-L. Lin (ASIZP), H. Endo, M. Matsunuma, and T. Naito (BSKU), T. Iwamoto and D. Catania (CAS), and K-T. Shao (NTOU) for access to comparative specimens; H. Saito and T. Makino (the Kyoto University Museum) for assistance in photography and examination of the Japanese specimen; H.-C. Ho (NMMB) for providing information on the type specimens of C. sheni; S. G. Poss (CAS) for comments on a draft of this paper; and G. Yearsley (Hobart) for editing the English text. This study was supported by a Grantin-Aid for Research Activity Start-up from JSPS KAKENHI (16H06896).

\section{References}

CAS (California Academy of Sciences). 2017. CAS Ichthyology Collection Database. Available at http://researcharchive.calacademy.org/ research/Ichthyology/collection/index.asp (29 September 2017).

Chiou, M.-L., Shao, K.-T., and Iwamoto, T. 2004. A new species, Caelorinchus sheni, and 19 new records of grenadiers (Pisces: Gadiformes: Macrouridae) from Taiwan. Zoological Studies 43: 35-50.

Eschmeyer, W. N., Fricke, R., and van der Laan, R. (Eds) 2017. Cata$\log$ of Fishes: genera, species, references. Available at http:// researcharchive.calacademy.org/research/ichthyology/catalog/ fishcatmain.asp (29 October 2017).

Fricke, R. and Eschmeyer, W. N. 2017. A guide of fish collections in the Catalog of Fishes. Available at http://researcharchive.calacademy. org/research/ichthyology/catalog/collections.asp (29 September 2017).

Furuhashi, N., Tsubaki, K., Morii, Y., and Hashimoto, J. 2010. Demersal fish assemblages from the continental shelf margin to the upper continental slope, southwest of Nagasaki, Japan. Bulletin of the Faculty of Fisheries, Nagasaki University 91: 17-33. [In Japanese with English abstract]

Ho, H.-C. and Shao, K.-T. 2011. Annotated checklist and type catalog of fish genera and species described from Taiwan. Zootaxa 2957: $1-74$.

Iwamoto, T. 1970. The R/V Pillsbury deep-sea biological expedition to the Gulf of Guinea, 1964-65. 19. Macrourid fishes of the Gulf of Guinea. Studies in Tropical Oceanography 4: 316-431.

Iwamoto, T. 1990. Family Macrouridae. Pp. 90-317. In: Cohen, D. M., Inada, T., Iwamoto, T., and Scialabba, N. (Eds) FAO Species Catalogue, Vol. 10. Gadiform Fishes of the World. An Annotated and Illustrated Catalogue of Cods, Hakes, Grenadiers and Other Gadiform Fishes Known to Date. FAO, Rome.

Iwamoto, T. and Merrett, N. R. 1997. Pisces Gadiformes: Taxonomy of grenadiers of the New Caledonian region, southwest Pacific. Mémoires du Muséum National d'Histoire Naturelle 176: 473-570.

Iwamoto, T., Nakayama, N., Shao, K.-T., and Ho, H.-C. 2015. Synopsis 
of the grenadier fishes (Gadiformes; Teleostei) of Taiwan. Proceedings of the California Academy of Sciences 62: 31-126.

Iwamoto, T. and Sazonov, Y. I. 1988. A review of the southeastern Pacific Coryphaenoides (sensu lato) (Pisces, Gadiformes, Macrouridae). Proceedings of the California Academy of Sciences 45: 35-82.

Iwamoto, T. and Williams, A. 1999. Grenadiers (Pisces, Gadiformes) from the continental slope of western and northwestern Australia. Proceedings of the California Academy of Sciences 51: 105-243.

Nakabo, T. and Kai, Y. 2013. Macrouridae. Pp. 493-512, 1872-1876. In: Nakabo, T. (Ed) Fishes of Japan with Pictorial Keys to the Species. Third Edition. Tokai University Press, Hadano. [In Japanese]

Nakayama, N. and Endo, H. 2017. A new species of the grenadier genus Coelorinchus (Actinopterygii: Gadiformes: Macrouridae) from the Timor Sea, Eastern Indian Ocean. Ichthyological Research 65: $12-20$.

Nakayama, N., Matsunuma, M., and Endo, H. 2015. Redescription of Coelorinchus tokiensis (Steindachner and Döderlein 1887) (Actinopterygii: Gadiformes: Macrouridae), with comments on its synonymy. Ichthyological Research 63: 247-259.

Okamura, O. 1970. Studies on the macrouroid fishes of Japan: Morphology, ecology and phylogeny. Reports of the Usa Marine Biological Station 17: 1-179.

Okamura, O. (Ed.) 1985. Fishes of the Okinawa Trough and the Adjacent Waters II. Japan Fisheries Resource Conservation Association,
Tokyo, pp. 417-718.

Okamura, O. and Kitajima, T. (Eds) 1984. Fishes of the Okinawa Trough and the Adjacent Waters I. Japan Fisheries Resource Conservation Association, Tokyo, $414 \mathrm{pp}$.

Shao, K.-T. 2017. The Fish Database of Taiwan. Available at http:// fishdb.sinica.edu.tw (1 September 2017).

Shao, K.-T., Iwamoto, T., Ho, H.-C., Cheng, T.-Y., and Chen, C.-Y. 2008. Species composition and distribution pattern of grenadiers (family Bathygadidae, Macrouridae, and Macrourididae [sic]) from Taiwan. Pp. 17-29. In: Orlov, A. M. and Iwamoto, T. (Eds) Grenadiers of the World Oceans: Biology, Stock Assessment, and Fisheries. American Fisheries Society Symposium 63. American Fisheries Society, Bethesda.

Shinohara, G., Sato, T., Aonuma, Y., Horikawa, H., Matsuura, K., Nakabo, T., and Sato, K. 2005. Annotated checklist of deep-sea fishes from the waters around the Ryukyu Islands, Japan. National Science Museum Monographs 29: 385-452.

Yamada, U., Tagawa, M., Kishida, S., and Honjo, K. 1986. Fishes of the East China Sea and the Yellow Sea. Seikai Regional Fisheries Research Laboratory, Nagasaki, XXVI+501 pp. [In Japanese]

Yamada, U., Tokimura, M., Horikawa, H., and Nakabo, T. 2007. Fishes and Fisheries of the East China and Yellow Seas. Tokai University Press, Hadano, xxiii+1262 pp. [In Japanese] 